\title{
Phytotoxic effects of the high molecular weight fraction of an aqueous leaf litter extract on barley root development
}

\author{
I. Brunner ${ }^{1}$ J. Luster ${ }^{1}$, M. Ochs ${ }^{2}$ and P. Blaser ${ }^{1}$ \\ ${ }^{1}$ Swiss Federal Institute for Forest, Snow and Landscape Research (WSL) CH-8903 Birmensdorf, Switzerland * \\ and ${ }^{2}$ Swiss Federal Institute for Environmental Science and Technology (EAWAG) CH-8600 Dübendorf, \\ Switzerland
}

Received 7 April 1995. Accepted in revised form 2 August 1995

Key words: adsorption behaviour, dissolved organic matter, leaf litter extract, molecular weight fractions, phytotoxicity, root development

\begin{abstract}
The root development of barley seedlings grown for one week in an aerated nutrient solution was studied in the presence of dissolved organic matter from an aqueous chestnut leaf litter extract. In particular, the different effects of low and high molecular weight fractions (small molecules: molecular weight $<1000$; large molecules: $>10,000$ ) of the leaf litter extract were examined. In the presence of large molecules root growth was inhibited, an irregular root tip morphology was observed, and $\mathrm{Ca}$ and $\mathrm{Mg}$ concentrations in the shoots were lower than in control plants. These phytotoxic effects were not caused by the formation of an impermeable layer of large molecules on the root surfaces that lower accessibility for nutrient cations as inferred from voltammetric experiments. A germination assay using spruce seeds, however, indicated allelochemical effects of large molecules, which exhibit a higher aromaticity than the small molecules as indicated by spectroscopic characterisation. In the growth experiments with small molecules, no influence on the root development of barley was evident, but an increase of $\mathrm{Ca}$ and $\mathrm{Mg}$ in the shoots was detected. During these growth experiments, a large amount of the small molecules, mainly simple phenols and amino acids, disappeared from the nutrient solution. The loss of small molecules was most likely the effect of mineralisation.
\end{abstract}

Abbreviations: DOC - dissolved organic carbon, DOM - dissolved organic matter, LLE - leaf litter extract, MW molecular weight, HMDE - hanging mercury drop electrode

\section{Introduction}

Dissolved organic matter (DOM) in the soil solution has a major influence on soil formation and plant nutrition because of its chemical reactivity and mobility in the soil profile (Blaser, 1994; Bloomfield, 1964; Bruckert, 1970). The sources of chemically active DOM in the soil solution are excretions from microorganisms and plant roots, leaching from the canopy as well as the litter mat, and, to a minor extent, humus mineralisation (Blaser, 1994; DeLong and Schnitzer, 1955; Lutwick and DeLong, 1954).

\footnotetext{
* Fax no: +4117392215
}

Dissolved organic substances originating from leaf litter or humus can influence the development of plants. Humic substances mostly have a stimulatory effect on plant growth (Chen and Aviad, 1990; Vaughan et al., 1985). In contrast, substances originating from aqueous litter extracts from trees, shrubs, grasses, or ferns, mostly negatively affect plant growth (Einhellig, 1986; Fisher, 1987; Mallik, 1992; Nilsson et al., 1993; Rice, 1984). In a detailed investigation, Grimvall et al. (1991) attributed the inhibitory effect on root growth by the runoff of a forested catchment mainly to the high molecular weight fraction of DOM.

The aim of the present study was to investigate the influence of low and high molecular weight fractions 
of DOM on plant root development, using barley as the model plant. As model for DOM in the soil solution, an aqueous chestnut leaf litter extract (LLE) was chosen because of its well characterised structural- and complexation-chemical properties (Blaser et al., 1984; Blaser and Sposito, 1987; Luster, 1990; Luster et al., 1994). Spectroscopic, analytical-chemical and biological approaches were used to elucidate possible interactions between organic molecules and root surfaces. The formation of a layer of organic molecules on root surfaces may lower the permeability for nutrient elements (Blaser, 1994). In addition, organic molecules can react specifically with roots which is known as allelochemical interference (Fischer, 1987; Rice, 1984). Both mechanisms can have an inhibitory effect on plant root development.

\section{Materials and methods}

Chemicals, labware, elemental analysis and spectroscopy

All chemicals were reagent grade. Water used for seed germination, preparation of nutrient solutions and extraction of leaf litter was purified by a Millipore Milli-Q plus water system. Before each use, extraction bottles and growth buckets were cleaned in four steps with $0.1 M \mathrm{NaOH}$, purified water, $1 M \mathrm{HCl}$, and purified water. Filters for the preparation of LLE were washed with $1 \mathrm{M} \mathrm{HCl}$ followed by thorough rinsing with purified water. Membranes used for molecular filtration were cleaned and stored according to the manufacturers recommendations (Amicon, Scientific Systems Division, Danvers, MA, USA).

Elemental concentrations were measured as follows: dissolved organic carbon (DOC) on a Shimadzu TOC-500, total carbon and nitrogen in solid samples on a Carlo Erba Instruments NA-1500 Series 2, other elements in LLE and fractions of it or in digests of roots and shoots by inductively-coupled plasma optical emission spectrometry (ARL 3580). The digests were obtained by dissolving the ash from dry combustion at $500{ }^{\circ} \mathrm{C}$ in $0.1 \mathrm{M} \mathrm{HNO}_{3}$.

Molecular absorption and fluorescence spectra were recorded on a Shimadzu UV-40 and a Shimadzu RF-5000 spectrometer, respectively, using quartz cells (path length $1 \mathrm{~cm}$ ). Prior to recording the spectra, sample solutions were diluted to a DOC concentration of 20 $\mathrm{mg} \mathrm{kg}^{-1}$ or less and adjusted to $\mathrm{pH} 4$. Molar absorption coefficients, $\varepsilon_{\mathrm{c}}$, were calculated by dividing the absorbance by the molar carbon concentration in solution.

For ${ }^{1} \mathrm{H}$-nuclear magnetic resonance (NMR) spectroscopy, $10 \mathrm{mg}$ of freeze-dried sample were dissolved in $600 \mu \mathrm{L} \mathrm{D} \mathrm{D}_{2} \mathrm{O}$ to which a drop of $1 \mathrm{M} \mathrm{NaOD}$ was added. Spectra were recorded on a Bruker AC200 spectrometer operating at $200 \mathrm{MHz}$ frequency. About 1000 scans with an acquisition time of $4.1 \mathrm{~s}$ were accumulated. Chemical shifts were referenced to external tetramethyl-silane.

\section{Preparation and molecular filtration of leaf litter extracts ( $L L E)$}

Leaf litter was collected from beneath a chestnut tree (Castanea sativa Mill.) at the WSL test site Copera in southern Switzerland. The fresh material was dried at $105{ }^{\circ} \mathrm{C}$ and ground using an ultracentrifugal mill with a W-coated rotor and a $1 \mathrm{~mm}$ sieve (Blaser et al., 1984). The extraction was performed by purging a suspension of $2.5 \mathrm{~g}$ dried powder and $100 \mathrm{~g}$ water in a polypropylene bottle with nitrogen for $15 \mathrm{~min}$ and shaking it on an end-over-end shaker for about $15 \mathrm{~h}$. The suspension was then filtered through a sequence of Schleicher and Schuell 589/1, 589/3 and ME25 (0.45 $\mu \mathrm{m})$ filters.

Molecular filtration was carried out in the diafiltration mode (washing technique, cf. Buffle et al., 1978) using Amicon TCF-10A thin channel systems. Aliquots of $200 \mathrm{~g} \mathrm{LLE}$ were filtered at an excess pressure of 10 to $15 \mathrm{kPa}$ through an Amicon YM10 filter (nominal molecular weight cut-off MWCO $=10,000$ ) using $1 \mathrm{~L}$ of $10^{-4} \mathrm{M} \mathrm{HClO}_{4}(\mathrm{pH} 4)$ as washing solution. The filtrate was concentrated on a rotary evaporator to $200 \mathrm{~g}$ and then filtered at an excess pressure of 15 to $25 \mathrm{kPa}$ through an Amicon YM1 (MWCO 1000) filter, again using $1 \mathrm{~L}$ of $10^{-4} \mathrm{M} \mathrm{HClO}_{4}(\mathrm{pH} 4)$ as washing solution. Thus, three fractions were obtained with molecular weight $(\mathrm{MW})>10,000$ (large molecules), $1000<\mathrm{MW}<10,000$ (medium molecules), and MW $<1000$ (small molecules), respectively. For all experimental work, only the fractions with MW $<1000$ and $>10,000$ were used.

\section{Growth of barley roots}

Barley seeds (Hordeum vulgare L. var. Flica) were spread on a square polyester net (side length $9 \mathrm{~cm}$, mesh size $3 \mathrm{~mm}$, styrofoam swimmers on each side) floating on water. For germination, this set-up was placed in a growth chamber with a constant temper- 
ature of $20{ }^{\circ} \mathrm{C}, 70 \%$ humidity and $16 \mathrm{~h}$ illumination (PAR: $100 \mu \mathrm{mol} \mathrm{m}^{-2} \mathrm{~s}^{-1}$ ) per day. After 4 days, ungerminated seeds were removed and the number of seedlings reduced to twenty. These selected seedlings were placed together with the polyester raft into a $3 \mathrm{~L}$ polycarbonate bucket containing $2 \mathrm{~L}$ aerated nutrient solution ( $7.5 \mathrm{~m} M \mathrm{KNO}_{3}, 3.25 \mathrm{mM} \mathrm{Mg}\left(\mathrm{NO}_{3}\right)_{2}, 5 \mathrm{~m} M$ $\left.\mathrm{Ca}\left(\mathrm{NO}_{3}\right)_{2}\right)$ and LLE or a molecular weight fraction at a DOC concentration between 0 and $40 \mathrm{mg} \mathrm{kg}^{-1}$. The solution $\mathrm{pH}$ was set to 4 and adjusted daily. After a growth period of 7 days under the same conditions as during germination, the plants were harvested. In general, treatments were carried out in duplicate.

For each treatment, the total root lengths of ten randomly selected plants were averaged. Selected root tips were examined with a dissecting microscope and by low-temperature scanning electron microscopy using a Balzers SCU 020 scanning cryopreparation unit and a Philips SEM 515 according to Müller et al. (1991) and Scheidegger et al. (1991). Roots and shoots of all twenty plants per treatment were dried at $60^{\circ} \mathrm{C}$ for 3 days and ground. Samples from mixtures of all powdered shoots were then used for elemental analysis.

\section{Adsorption of LLE at a Hg electrode and interaction with $C d^{2+}$}

A hanging $\mathrm{Hg}$ drop electrode (HMDE) was used as a model surface to study adsorption of organic compounds by root surfaces. Although the two surfaces cannot be compared directly, the major processes responsible for adsorption of organic compounds (hydrophobic expulsion from solution and attraction by electrostatic forces) are assumed to be comparable. The surface charge of roots is supposed to be mainly negative due to the presence of pectin-like structures of the mucigel (Rougier, 1981), but minor contributions of positively charged functional groups cannot totally be excluded. Thus, conditional adsorption isotherms for the adsorption of small and large molecules of the LLE by the HMDE were recorded at negatively and positively charged electrodes. In addition, the influence of a layer of these small or large molecules adsorbed at the $\mathrm{Hg}$ electrode on the reduction and oxidation wave of $\mathrm{Cd}$ was studied. This experiment served to assess the permeability of an adsorbed layer of organic molecules for $\mathrm{Cd}^{2+}$ (e.g. Batina and Cosovic, 1987; Brezonik et al., 1976; Plavsic et al., 1991). This permeability may influence the diffusive transport of cations to the root surface which is a first step in nutrient uptake. Cadmium $^{2+}$ was used as an electrochemically acces- sible model ion for the macronutrient $\mathrm{Ca}^{2+}$. Cadmium exhibits a well-defined, reversible two-electron reduction wave at a half-wave potential of $-0.6 \mathrm{~V}$ which is close to the potential of maximum adsorption of most natural organic compounds (Cosovic, 1985), whereas the redox potential of $\mathrm{Ca}^{2+}$ lies outside the range that is accessible with a $\mathrm{Hg}$-electrode. The two cations, $\mathrm{Ca}^{2+}$ and $\mathrm{Cd}^{2+}$, are chemically similar in terms of effective ionic radii and stability constants for complexes with O-donor ligands (Martin, 1984). In addition, it has been observed that the affinity of proteins for $\mathrm{Ca}^{2+}$ and $\mathrm{Cd}^{2+}$ is similar (Behra and Gall, 1991; Cox et al., 1984).

Experiments were performed with a Metrohm E 506 polarograph connected to a Metrohm VA $663 \mathrm{elec}-$ trode stand. The latter was equipped with (1) a multimode $\mathrm{Hg}$ working electrode used as a HMDE, (2) a $\mathrm{Ag} / \mathrm{AgCl} / 3 M \mathrm{KCl}$ reference electrode connected to the electrolyte solution through a salt bridge $(0.1 \mathrm{M}$ $\mathrm{NaNO}_{3}$ ), and (3) a $\mathrm{Pt}$ counter electrode. Adsorption of LLE by the $\mathrm{Hg}$ surface was studied using phase selective alternating current voltammetry (for details see Jehring, 1974, or Bond, 1980). Experiments were carried out with stirred electrolyte solutions $(0.1 \mathrm{M}$ $\mathrm{NaNO}_{3}$ ) adjusted to $\mathrm{pH} 2.1$ or 4.0 containing molecular weight fractions of LLE in DOC concentrations of up to $20 \mathrm{mg} \mathrm{kg}^{-1}$. A constant electrode potential of $-0.4 \mathrm{~V}$ (vs. $\mathrm{Ag} / \mathrm{AgCl}$ ) resulted in a hydrophobic $\mathrm{Hg}$ surface with a slightly positive charge, whereas a potential of $-0.8 \mathrm{~V}$ led to a slightly negative surface. Amplitude and frequency of the superimposed alternating voltage were $10 \mathrm{mV}$ and $75 \mathrm{~Hz}$, respectively, and the phase angle $\varphi$ was $90^{\circ}$. The surface coverage $\Theta$ of the $\mathrm{Hg}$-electrode after an accumulation time of $60 \mathrm{~s}$ was calculated as follows: $\Theta=\left(\mathrm{i}_{c, 0}-\mathrm{i}_{c, \Theta}\right) /\left(\mathrm{i}_{c, 0}-\right.$ $\left.i_{c, L L E}\right)$. Here, $i_{c, 0}, i_{c}, \Theta$, and $i_{c, L L E}$ refer to the capacitive current, $i_{c}$, measured with an electrode surface that is uncovered, partially covered, and completely covered by LLE, respectively. The latter was defined as $i_{c}$ measured after an accumulation time of $30 \mathrm{~min}$ with DOC $=20 \mathrm{mg} \mathrm{kg}^{-1}$. The influence of LLE fractions adsorbed by the $\mathrm{Hg}$ surface on the reduction (cathodic wave) and oxidation (anodic wave) of $\mathrm{Cd}^{2+}$ was investigated under the same experimental conditions as described above except $\mathrm{pH}$, which was 2.1 to avoid possible competition by complexation in solution by dissolved organic molecules. The concentration of $\mathrm{Cd}$ in the electrolyte solution was $1 \times 10^{-4} M$. To study the reduction process, the organic molecules were accumulated for $60 \mathrm{~s}$ at the slightly positive $\mathrm{Hg}$ surface by applying a constant potential of $-0.4 \mathrm{~V}$. Then, $\mathrm{Cd}^{2+}$ 
-ions in the electrolyte solution were reduced at the modified electrode surface by scanning the potential towards more negative values $(-0.4 \mathrm{~V} \rightarrow-0.8 \mathrm{~V})$. In order to investigate the oxidation process, the initial potential was set to $-0.8 \mathrm{~V}$. In this case, the reduction of $\mathrm{Cd}^{2+}$ occurred simultaneously with the adsorption of the organic material, and, during a scan towards positive potentials $(-0.8 \mathrm{~V} \rightarrow-0.4 \mathrm{~V}), \mathrm{Cd}^{0}$ was oxidised at the modified electrode surface. Differential pulse voltammetry and differential pulse anodic stripping voltammetry, both with a scan rate of $20 \mathrm{mV}$ $\mathrm{s}^{-1}$ and a pulse amplitude of $10 \mathrm{mV}$, were used to quantify the resulting cathodic and anodic waves. The results are given in terms of normalised peak heights $\left(i_{p} / i_{p 0}\right.$, where $i_{p 0}$ and $i_{p}$ stand for the peak current of the $\mathrm{Cd}^{2+}$-wave in the absence and presence of LLE, respectively).

\section{Seed germination bioassay}

The methodology was adapted from Leather and Einhellig (1986) and Pellissier (1990). Molecular weight fractions of the LLE were sterilised by $0.2 \mu \mathrm{m}$ filtration and added to hot autoclaved water agar in DOC concentrations of 5 or $40 \mathrm{mg} \mathrm{kg}^{-1}$. Twenty $\mathrm{mL}$ aliquots of these or DOC-free agar suspensions were poured into Petri dishes. After cooling, 20 seeds of Norway spruce (Picea abies (L.) Karst.) were placed randomly on the solid surface under aseptic conditions. Seeds were collected in 1977 from a single tree at Tägerwilen in the eastern part of Switzerland and surface sterilised for $20 \mathrm{~min}$ with $30 \% \mathrm{H}_{2} \mathrm{O}_{2}$. Dishes were sealed with parafilm and stored at room temperature. Germination of seeds, defined by radicle length exceeding seed length, was recorded daily. Germinated seeds were marked on the dishes and counted cumulatively for 27 days. Statistical analyses for each treatment consisting of 10 replicates were carried out using standard analysis of variance. Least significant differences were calculated at $p \leq 0.05$ using Fisher's PLSD test.

\section{Results}

Development of barley roots in the growth experiments

Mean plant root length after 4 days of germination was $9.0 \pm 0.9 \mathrm{~cm}$, and reached a value of $71.3 \pm 9.6 \mathrm{~cm}$ after 7 days of exposure in the nutrient solution (Fig. 1). Increasing additions of chestnut LLE to the nutri-

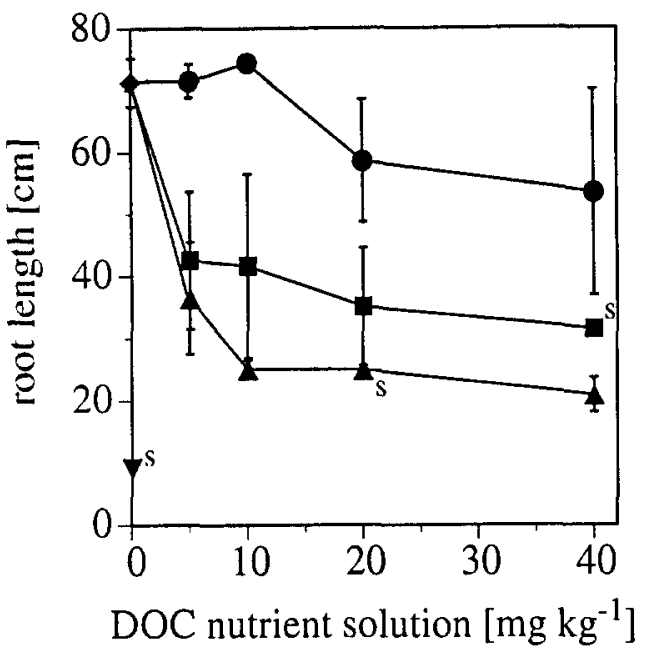

Fig. 1. Mean total root length of 10 plants at the end of growth experiments vs. concentration of DOC from chestnut LLE ( $\square$ ) or its molecular weight (MW) fractions (MW<1000 (O) and $\mathrm{MW}>$ $10,000(\Delta))$ added at the beginning. Root length measured at the end of the control experiment $(\boldsymbol{})$ and at the end of the germination phase $(\boldsymbol{\nabla})$ are shown. Error bars indicate the standard deviation of two repetitions, an (s) marks single values.

ent solution led to a reduction of the root length (Fig. 1). Large LLE molecules (MW>10,000) in concentrations of $5 \mathrm{mg} \mathrm{kg}^{-1}$ DOC or more led to a drastic reduction of root length (Fig. 1), whereas the addition of small molecules $(\mathrm{MW}<1000)$ only in concentrations of $20 \mathrm{mg} \mathrm{kg}^{-1}$ or more led to a slight reduction of root length.

Root tips developed in nutrient solutions containing low or high concentrations of the small molecules showed a morphology similar to those of control plants, with regular root caps and root cap cells (Figs. 2a, b). Root tips from plants grown in nutrient solutions containing the large molecules at various concentrations were thickened and brown coloured, and displayed a disordered arrangement of root cap cells (Figs. 2c, d). In addition, root hairs were collapsed or missing. In contrast to the roots, the development of shoots was not affected by the addition of LLE to the nutrient solutions (data not shown).

\section{Element contents of shoots at the end of the growth experiments}

Increasing concentrations of small molecules of the LLE in the nutrient solution led to increased $\mathrm{Ca}, \mathrm{Mg}$, and $\mathrm{Mn}$ concentrations in shoots (Fig. 3). Higher concentrations of large molecules led to slightly lower 




Fig. 2. Low-temperature scanning electron micrographs of barley root tips grown in nutrient solutions with chestnut LLE or its molecular wcight $(\mathrm{MW})$ fractions at various DOC concentrations $(S c a l e=0.1 \mathrm{~mm}$ ). a). Root tip grown without LLE added. Note the regular appearance of the root cap and the root cap cells. b). Root tip grown at $40 \mathrm{mg} \mathrm{kg}^{-1} \mathrm{DOC}$ of small molecules (MW>1000). Note the regular appearance of the root cap and the root cap cells. c). Root tip grown at $10 \mathrm{mg} \mathrm{kg}^{-1} \mathrm{DOC}$ of large molecules $(\mathrm{MW}>10,000)$. Note disordered arrangement of the root cap and the root cap cells. d). Root tip grown at $40 \mathrm{mg} \mathrm{kg}^{-1} \mathrm{DOC}$ of large molecules (MW>10,000). Note disordered arrangement of the root cap and the root cap cells. 
Table 1. Molecular characteristics of DOM in the chestnut LLE and its molecular weight (MW) fractions. (n.d.: not determined)

\begin{tabular}{|c|c|c|c|c|c|c|c|c|c|c|}
\hline & \multirow{3}{*}{$\begin{array}{l}\text { DOC } \\
\text { conc. }\end{array}$} & \multirow[t]{2}{*}{$\mathrm{C}$} & \multirow[t]{2}{*}{$\mathbf{N}$} & \multicolumn{5}{|c|}{$\mathrm{C} / \mathrm{N}$ Distribution of organic structures ( ${ }^{1} \mathrm{H}$ NMR spectroscopy) } & \multicolumn{2}{|c|}{ Molar absorption coefficient } \\
\hline & & & & & $\begin{array}{l}\text { Alkyl } \\
\text { groups c }\end{array}$ & $\begin{array}{l}\text { Alkyl groups } \\
\text { carbonyl or aro } \\
\text { structures }\end{array}$ & $\begin{array}{l}\text { Carbo- } \\
\text { hydrates }\end{array}$ & $\begin{array}{l}\text { Aromatic } \\
\text { structures }\end{array}$ & $\varepsilon_{\mathrm{c}}(280 \mathrm{~nm})$ & $\varepsilon_{\mathrm{c}}(400 \mathrm{~nm})$ \\
\hline & & $(\%)$ & $(\%)$ & & $(\%)$ & $(\%)$ & $(\%)$ & $(\%)$ & \multicolumn{2}{|c|}{$\left.\left(\mathrm{kg}(\mathrm{mol} \mathrm{cm})^{-1}\right)\left(\mathrm{kg}(\mathrm{mol} \mathrm{cm})^{-1}\right)\right)$} \\
\hline Total extract & $\begin{array}{l}1750 \pm 1704 \\
\left(\mathrm{mg} \mathrm{kg}^{-1}\right)\end{array}$ & $42.6 \pm 0.9$ & n.d. & - & 14 & 16 & 63 & 8 & $331 \pm 48$ & $39 \pm 6$ \\
\hline MW $<1000$ & $35 \pm 4(\%)$ & $39.5 \pm 1.20$ & $.61 \pm 0.05$ & 65 & 14 & 18 & 61 & 8 & $313 \pm 37$ & $20 \pm 2$ \\
\hline $\mathrm{MW}>10,000$ & $44 \pm 4(\%)$ & $44.7 \pm 0.50$ & $.55 \pm 0.01$ & 81 & 14 & 11 & 65 & 11 & $323 \pm 64$ & $41 \pm 12$ \\
\hline
\end{tabular}

Table 2. Contents of selected elements $\left(\mathrm{g} \mathrm{kg}^{-1}\right.$ $\mathrm{C} ; \pm \mathrm{SD}$ ) in the chestnut LLE and its molecular weight (MW) fractions

\begin{tabular}{lllll}
\hline & $\mathrm{Ca}$ & $\mathrm{Mg}$ & $\mathrm{Mn}$ & $\mathrm{P}$ \\
\hline Total extract & $19 \pm 8$ & $14 \pm 3$ & $2.6 \pm 0.6$ & $2.6 \pm 0.7$ \\
$\mathrm{MW}<1000$ & $28 \pm 8$ & $23 \pm 6$ & $4.0 \pm 1.1$ & $7.4 \pm 1.9$ \\
$\mathrm{MW}>10,000$ & $18 \pm 6$ & $13 \pm 2$ & $2.5 \pm 0.1$ & $0.4 \pm 0.1$ \\
\hline
\end{tabular}

concentrations of $\mathrm{Ca}$ and $\mathrm{Mg}$, and to slightly increased concentrations of $\mathrm{Mn}$ (Fig. 3). In the presence of total LLE, concentrations of selected elements in shoots in general were in between the concentrations measured in the corresponding experiments with small and large molecules (Fig. 3).

\section{LLE characteristics and changes during the growth experiments}

The chestnut LLE had a pH of $4.11 \pm 0.01$. The DOC concentration of the total extract was $1750 \mathrm{mg} \mathrm{kg}^{-1}$ with $44 \%$ corresponding to large and $35 \%$ to small molecules (Table 1). The $\mathrm{C}$ content of the low molecular fraction was distinctly lower than that of the high molecular fraction, whereas the $\mathrm{N}$ content of both fractions was similar (Table 1). According to ${ }^{1} \mathrm{H}-\mathrm{NMR}$ spectroscopy, small and large molecules were composed of about two-thirds of carbohydrates. The ratio of the content of alkyl groups to that of aromatic structures was 4.0 for small and 2.3 for large molecules (Table 1). The molar absorption coefficient, $\varepsilon_{\mathrm{c}}$, at 280 $\mathrm{nm}$ was about 300 for small and large molecules (Table
1). In contrast, at $400 \mathrm{~nm}$ the large molecules showed a higher molar absorption coefficient than the small molecules (Table 1). Concentrations of all elements in the LLE were higher in the low than in the high molecular weight fraction (Table 2). In addition, the $P$ concentration in the high molecular weight fraction was much lower than in the low molecular weight fraction, whereas for $\mathrm{Ca}, \mathrm{Mg}$, and $\mathrm{Mn}$ the differences were less pronounced (Table 2).

Figure 4 shows the DOC concentration in the nutrient solution measured at the end of the growth experiment vs. the DOC concentration of LLE or fractions of it added at the beginning of the experiment. At the end of the control experiment (without LLE) a DOC concentration of $3.2 \pm 0.3 \mathrm{mg} \mathrm{kg}^{-1}$ was found, which could be due to the presence of root exudates. Considering the presence of root exudates, in the experiments with small molecules, distinctly less DOC was measured at the end of the experiments than was added at the beginning. In experiments with large molecules or the total LLE, a distinctly smaller decrease of DOC was observed (Fig. 4). Figure 5 shows the change of the absorption spectra of the nutrient solutions during the growth experiments for the control without LLE added and for the experiments at an initial concentration of LLE fractions of $10 \mathrm{mg} \mathrm{kg}^{-1}$ DOC. In order to demonstrate the change of the LLE spectra alone, the spectrum at the end of the control experiment was subtracted from the spectra at the end of the experiments with LLE fractions. The spectra of the small and the large molecules at the beginning of the experiments were very similar. A change during the growth experiments, when considering the corrected spectra at the end of the experiments, consisted in both cases mainly of a decrease at shorter wavelengths, where simple 


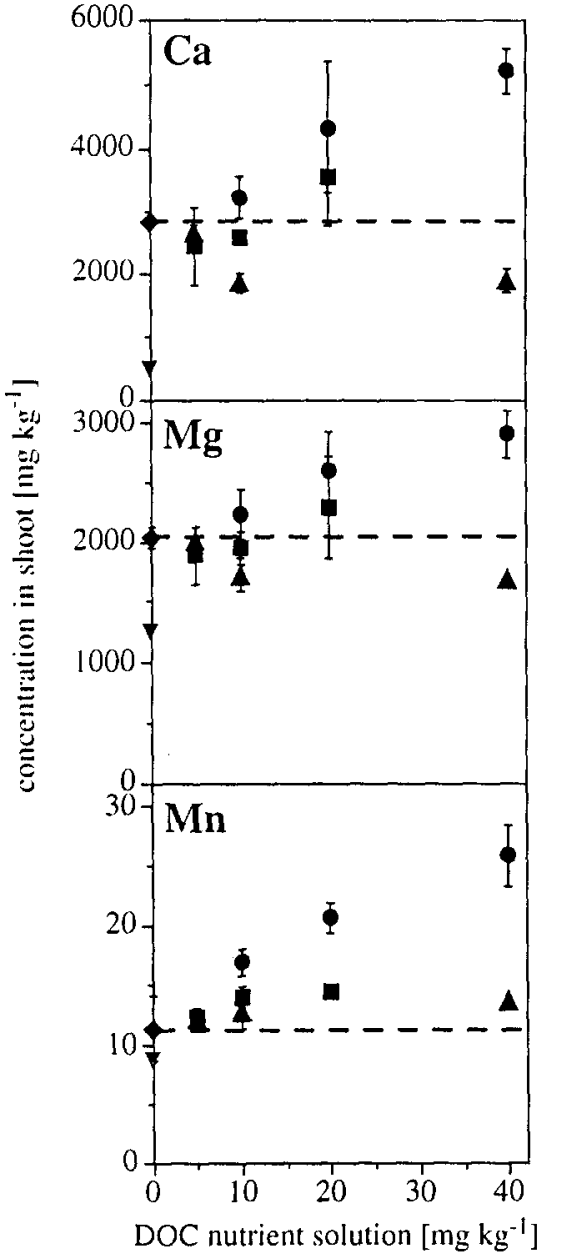

Fig. 3. Concentration of selected elements in shoots of barley at the end of the growth experiment vs. concentration of DOC from chestnut LLE ( $\square$ ) or its molecular weight (MW) fractions (MW<1000 $(\odot)$ and $M W>10.000(\Delta)$ ) added at the beginning. Element concentrations measured at the end of the control experiment $(\boldsymbol{})$ and at the end of the germination phase $(\boldsymbol{\nabla})$ are shown. Error bars indicate the standard deviation of two repetitions.

phenols and small conjugated ketons absorb (Pretsch et al., 1981). This decrease was much more pronounced for the small molecules than for the large molecules. In Figure 6 the change of the contour fluorescence spectra of the nutrient solution from the growth experiment with small molecules at a DOC concentration of $20 \mathrm{mg} \mathrm{kg}^{-1}$ is shown. The spectrum of the small molecules exhibited three major peaks with maxima at excitation/emission wavelength pairs (EEWP) of 275/325, 330/440 and 250/440 (in nm). The first peak is characteristic for the amino acids tyrosine and tryptophane, the second one can mainly be attributed to phenolic substances like simple phenols, coumarins,

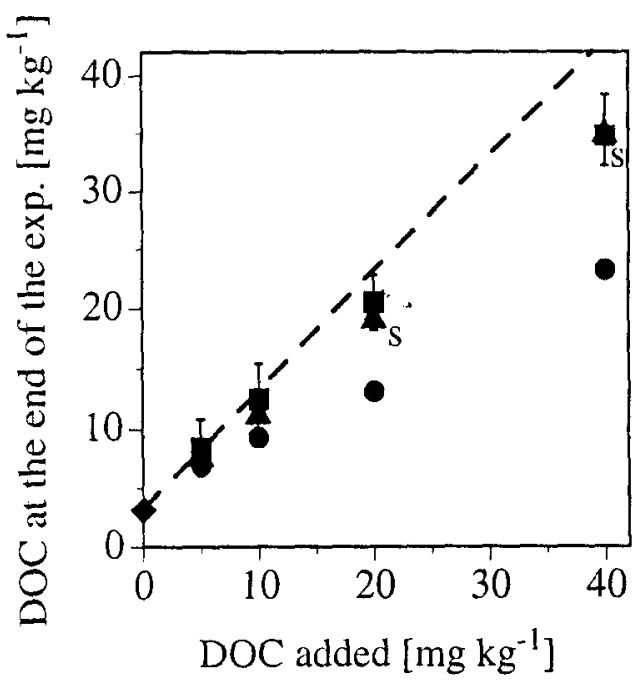

Fig. 4. DOC concentration in the nutrient solution measured at the end of the growth experiment vs. DOC added at the beginning for the control experiment $(\$)$ and the experiments with LLE $(\square)$ and its molecular weight (MW) fractions (MW $<1000$ (O) and $\mathrm{MW}>10,000$ (A)). Error bars indicate the standard deviation of two repetitions, an (s) marks single values.

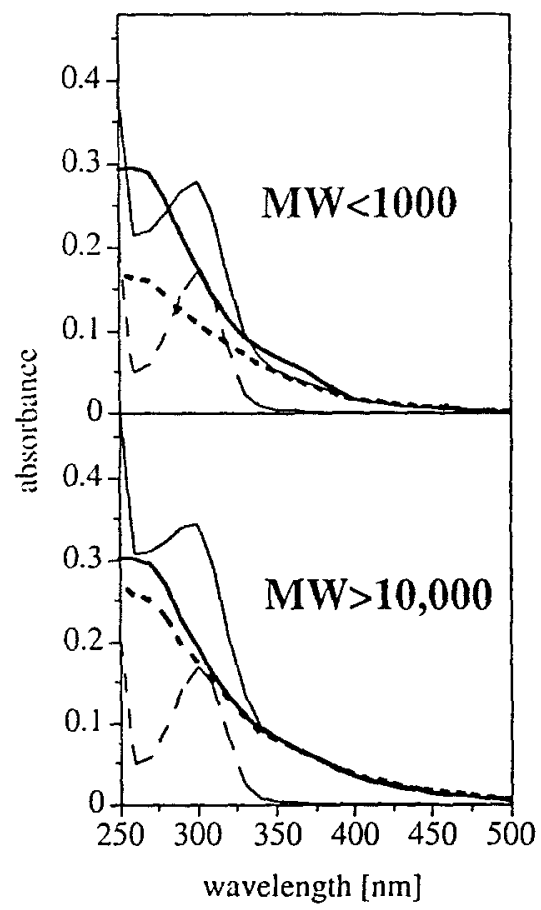

Fig. 5. Molecular absorption spectra of the nutrient solution measured at the beginning $(-$ ) and at the end $(-)$ of the growth experiments with $10 \mathrm{mg} \mathrm{kg}^{-1}$ DOC of molecular weight (MW) fractions of the LLE added. In addition, the spectrum at the end of the growth experiment (---) is shown that was corrected for the one at the end of the control experiment (- - - ). 


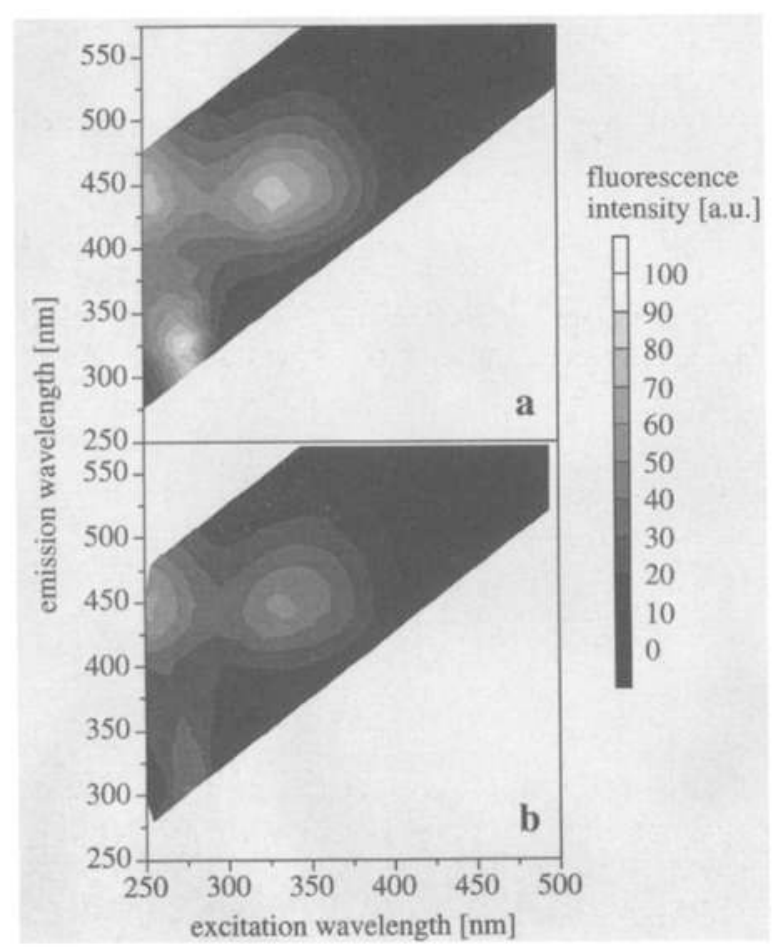

Fig. 6. Contour fluorescence spectra of the nutrient solution from the growth experiment with small molecules of the LLE (molecular weight $<1000$ ) added at a DOC concentration of $20 \mathrm{mg} \mathrm{kg}^{-1}$. a) Spectrum at the beginning of the experiment. b) Spectrum at the end of the experiment, corrected for the spectrum at the end of the control experiment without LLE.

or flavonoids (Senesi et al., 1991; Wolfbeis, 1985), whereas the nature of the substances responsible for the third peak is unknown. The comparison of this spectrum with the corrected spectrum at the end of the experiment showed a distinct decrease of the peak at EEWP 275/325. The decrease of the peak at EEWP $330 / 440$ was less pronounced, and the third one did not decrease at all. In contrast to the small molecules, the large molecules exhibited very little fluorescence (data not shown).

An almost equal loss of DOC and very similar changes of absorption and fluorescence spectra were observed in a control experiment with LLE but without plants (data not shown).

\section{Adsorption of LLE fractions by a HMDE}

For both the negatively (potential $-0.8 \mathrm{~V}$ ) and the positively (potential $-0.4 \mathrm{~V}$ ) charged electrode, a similar adsorption behavior of small and large molecules was found (Fig. 7a, b). A small difference was observed in

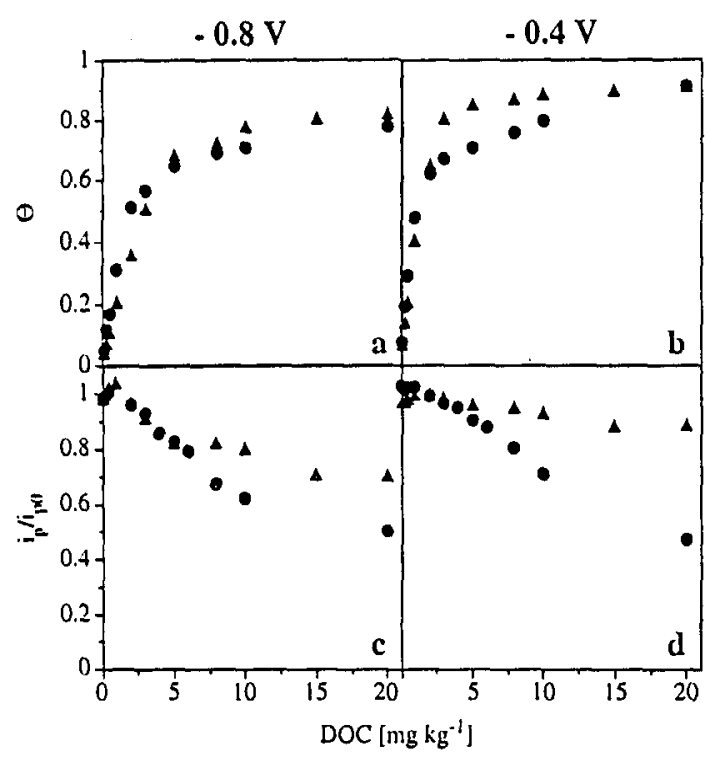

Fig. 7. Behaviour of the chestnut $\mathrm{LLE}$ at a hanging $\mathrm{Hg}$ drop electrode at a deposition potential of $-0.8 \mathrm{~V}(\mathrm{a}, \mathrm{c})$ and $-0.4 \mathrm{~V}(\mathrm{~b}, \mathrm{~d})$. a,b) Adsorption of small (molecular weight $<1000$, $)$ and large (molecular weight $>10,000, \mathbf{\Delta}$ ) molecules expressed as relative surface coverage of the $\mathrm{Hg}$ drop $(\Theta)$. c, d. Effect of an adsorbed layer of small ( ) and large ( 4 ) molecules on the anodic (oxidation, deposition potential $=-0.8 \mathrm{~V}$ ) and cathodic (reduction, deposition potential $=-0.4 \mathrm{~V}$ ) wave of $10^{-4} M \mathrm{Cd}^{2+}$, expressed as peak current of $\mathrm{Cd}^{2+}$ in the presence of $D O C\left(i_{p}\right)$ relative to peak current in the absence of DOC $\left(i_{p, 0}\right)$.

the case of the positively charged electrode in the DOC range $3-10 \mathrm{mg} \mathrm{kg}^{-1}$ (Fig. $7 \mathrm{~b}$ ). These results obtained at $\mathrm{pH} 2.1$ were similar to those at $\mathrm{pH} 4.0$ (data not shown). Both small and large molecules suppressed the cathodic (following adsorption at a positively charged electrode), as well as the anodic (following adsorption at a negatively charged electrode) wave of $\mathrm{Cd}^{2+}$ (Fig. $7 \mathrm{c}, \mathrm{d})$. At DOC concentrations $>5 \mathrm{mg} \mathrm{kg}^{-1}$, at which surface coverage by the organic molecules was $70 \%$ or higher, the suppression of both waves was stronger by the small than by the large molecules. The influence of the small molecules on the cathodic and anodic process was similar, whereas the large molecules showed a more pronounced inhibition of the anodic process.

\section{Seed germination bioassay on the influence of $L L E$ fractions}

Small molecules of the LLE had no significant influence on the germination of Norway spruce seeds (Table 3). The presence of large molecules, however, led to a reduction of the number of germinated seeds 
Table 3. Number of germinated spruce seeds (from a total of 20 seeds; \pm SE) after 7, 14, and 21 days on agar plates $(n=10)$ containing various molecular weight (MW) fractions of a chestnut LLE in various DOC concentrations. Different letters within columns indicate a significant difference $(p \leq 0.05)$

\begin{tabular}{lccll}
\hline & $\begin{array}{c}\text { DOC conc. } \\
\left(\mathrm{mg} \mathrm{kg}^{-1}\right)\end{array}$ & \multicolumn{3}{l}{ Days } \\
\cline { 3 - 5 } & & & 14 & 21 \\
\hline Control & 0 & $3.2 \pm 0.4 \mathrm{~b}$ & $18.5 \pm 0.4 \mathrm{a}$ & $19.1 \pm 0.3 \mathrm{a}$ \\
$\mathrm{MW}<1000$ & 5 & $2.4 \pm 0.5 \mathrm{~b}$ & $18.8 \pm 0.3 \mathrm{a}$ & $19.3 \pm 0.3 \mathrm{a}$ \\
$\mathrm{MW}<1000$ & 40 & $2.0 \pm 0.5 \mathrm{~b}$ & $17.4 \pm 0.5 \mathrm{a}$ & $18.6 \pm 0.5 \mathrm{a}$ \\
$\mathrm{MW}>10,000$ & 5 & $5.0 \pm 0.7 \mathrm{a}$ & $17.3 \pm 0.6 \mathrm{a}$ & $17.8 \pm 0.4 \mathrm{ab}$ \\
$\mathrm{MW}>10,000$ & 40 & $4.3 \pm 0.6 \mathrm{ab}$ & $15.1 \pm 0.8 \mathrm{~b}$ & $16.7 \pm 0.6 \mathrm{~b}$ \\
\hline
\end{tabular}

after 14 and 21 days which was significant at high DOC concentrations.

\section{Discussion}

The presence of organic molecules from an aqueous extract of chestnut leaf litter had a negative influence on the development of barley roots in terms of length and morphology. The use of different molecular weight fractions of the LLE revealed that small molecules had only little effect on the root length and no effect on root tip morphology whereas large molecules strongly suppressed root growth and led to an irregular root tip morphology. The phytotoxic effects of the large molecules were visible at DOC concentrations as low as $5 \mathrm{mg} \mathrm{kg}^{-1}$. Similar observations were made by Grimvall et al. (1991), who investigated the influence of the runoff of an old spruce stand on the root development of cucumber. The observed inhibitory effect was mainly attributed to molecules with a molecular weight $>1000$. For humic substances extracted from a composted sewage sludge a contrary observation was made (Dell' Amico et al., 1994). An inhibitory effect on the shoot and root dry weight of barley was shown for small molecules $(M W<1000)$, whereas a stimulation of growth was detected for larger molecules (MW>1000) and for the total extract. These contradictory observations suggest that the behavior of the MW fractions, of DOM on plant development depends on the source of the DOM. Furthermore, authors reporting on phytotoxic effects of water-extractable organic leaf litter substances give little information on the mechanisms involved (Fisher, 1987; Grimvall et al., 1991; Mallik, 1992; Nilsson et al., 1993).
The inhibitory effect of large molecules on root development can be the result of either physicalchemical or structural-chemical characteristics, which can be expressed in two hypotheses. Hypothesis a) states that, in contrast to small molecules, large molecules form an impermeable layer on root surfaces, and, therefore, reduce the physical accessibility of the root surface for nutrient cations. This is based on the concept that adsorption of DOM increases with increasing polyfunctionality of the organic molecules (Blaser, 1994; Ochs et al., 1993; Tipping, 1990). Hypothesis b) states that specific chemical interactions between large molecules of the LLE and the roots lead to growth inhibition and irregular root morphology. Such phytotoxic effects of plant produced chemical inhibitors have widely been observed and defined as allelochemical interactions (Fisher, 1987; Rice, 1984; Rizvi et al., 1992).

Voltammetric data give direct information on the tendency of molecules to form an impermeable layer on a surface (Cosovic and Vojvodic, 1989; Plavsic and Cosovic, 1991), and thus, they allow to test hypothesis a). In general, the LLE fractions displayed the same qualitative pattern of adsorption to the HMDE and inhibition of the $\mathrm{Cd}$ wave as humic substances (Plavsic and Cosovic, 1991). With respect to the affinity of the molecules to the $\mathrm{Hg}$-surface, the conditional adsorption isotherms showed a similar behaviour for both small and large molecules irrespective of the surface charge. The relative peak currents measured at a surface coverage of $70 \%$, or higher indicate a better $\mathrm{Cd}^{2+}$ permeability of an adsorbed layer of large molecules than of a layer of small molecules, independent of the electrode surface charge. Thus, the results of the voltammetric experiments contradict hypothesis a) that large molecules form a more impermeable layer on root surfaces than small molecules. Considering elemental concentrations in the shoots, the increase of $\mathrm{Mn}$ in the presence of large molecules supports the results of the voltammetric permeability experiment, whereas the decrease of $\mathrm{Ca}$ and $\mathrm{Mg}$ is in contradiction. In summary, both the voltammetric data and the results of the element concentrations in the shoots are partly contradictory and mainly argue against hypothesis a).

The results of the seed germination bioassay and the microscopic evaluation of the root morphology give clues on specific chemical interactions and thus allow to test hypothesis b). The significant inhibitory effect of the high molecular weight LLE fraction suggests an allelochemical effect of certain large 
molecules, and thus, argues in favour of this hypothesis. Spectroscopic characterisation revealed that large molecules in the LLE exhibit a higher aromaticity than the small molecules. This higher aromaticity is mainly due to highly-conjugated aromatic structures such as coumarins, tannins, or flavonoids (Pretsch et al., 1981; Siqueira et al., 1991), as indicated by the comparison of the molar absorption coefficients at 280 and $400 \mathrm{~nm}$. It is known that such compounds exhibit allelochemical effects on plant processes (Rice, 1984; Siqueira et al., 1991). In particular, cell division and elongation can be affected (Einhellig, 1986) and result in an abnormal radical growth (Mallik, 1992).

Besides the inhibitory effect of large molecules on the root development, an increased uptake of elements into shoots in the presence of small molecules was observed. Because Mn was not included in the basic nutrient solution, the presence of this element can be attributed to uptake of residual Mn of the LLE, either in organically complexed form together with the small organic molecules or after release from these molecules following mineralisation. Both processes are consistent with the loss of small molecules detected by DOCbalance. The change of the molecular absorption spectra indicated a preferential loss of simple phenols and small conjugated ketones, and, in addition, the change of the fluorescence spectrum showed a marked loss of amino acids. The almost equal loss of DOC and the similar changes of absorption and fluorescence spectra in the control experiment without plants strongly suggest that the loss of small molecules of the LLE can be attributed mainly to mineralisation and not to uptake by roots. This conclusion is supported by much higher $P$ contents of the low molecular weight fraction. Phosphorus is a key element for microbial growth that has not been added in the basic nutrient solution. However, the increase of the $\mathrm{Ca}$ and $\mathrm{Mg}$ concentrations in the shoots cannot be explained simply by release from LLE molecules following mineralisation, because it is not proportional to the enhancement of the concentration of these elements in the nutrient solution by the residual contents of the LLE. Different mechanisms have been proposed for a comparable stimulatory effect on the uptake of nutrient cations by humic substances. They either form complexes with the cations that are taken up by plants, or they directly influence uptake mechanisms at root surfaces, plant metabolic processes, or enzyme activities (Chen and Aviad, 1990; Vaughan et al., 1985).

In conclusion, small and large molecules of LLE adsorb at root surfaces to a similar extent. The inter- action between the adsorbed large molecules and the roots leads to an inhibition of root growth, to an irregular root tip morphology, and to a slight decrease of $\mathrm{Ca}$ and $\mathrm{Mg}$ concentrations in the shoots. These effects cannot be attributed to inhibition of nutrient uptake due to formation of an impermeable layer by adsorbed large molecules, but rather to a specific phytotoxic influence of highly conjugated phenolic substances. Furthermore, small molecules stimulate uptake of the macronutrients $\mathrm{Ca}$ and $\mathrm{Mg}$.

\section{Acknowledgements}

We thank C Scheidegger for taking the scanning electron micrographs, B Milakovic and U Beutler for helping with the experimental work, D Pezzotta and his crew for elemental analyses, and C Ammann from the Laboratory for Inorganic Chemistry of the ETH Zürich for recording the ${ }^{1} \mathrm{H}-\mathrm{NMR}$ spectra. The authors thank A U Gehring and S Ochs for reviewing the manuscript and correcting the English text.

\section{References}

Batina N and Cosovic B 1987 Adsorption of a mixture of sodium dodecyl sulphate and dodecyl alcohol on a mercury electrode and its effect on the electrochemical processes of cadmium(II) in sodium chloride solution. J. Electroanal. Chem. 227, 129-146.

Behra R and Gall R 1991 Calcium/calmodulin-dependent phosphorylation and the effect of cadmium in cultured fish cells. Comp. Biochem. Physiol. 100C, 191-195.

Blaser P 1994 The role of natural organic matter in the dynamics of metals in forest soils. In Humic Substances in the Global Environment and Implications on Human Health. Eds. N Senesi and T M Miano. pp 943-960. Elsevier Science BV, Amsterdam, the Netherlands.

Blaser P and Sposito G 1987 Spectrofluorometric investigation of trace metal complexation by an aqueous chestnut leaf litter extract. Soil Sci. Soc. Am. J. 51, 612-619.

Blaser P, Sposito G and Holtzclaw K M 1984 Composition and acidic functional group chemistry of an aqueous chestnut leaf litter extract. Soil Sci. Soc. Am. J. 48, 278-283.

Bloomfield C 1964 Organic matter and soil dynamics. In Experimental Pedology. Eds. E G Hallsworth and D V Crawford. pp 257-266. Butterworths, London, UK.

Bond A M 1980 Modern Polarographic Methods in Analytical Chemistry. Marcel Dekker, New York, USA.

Brezonik P L, Brauner P A and Stumm W 1976 Trace metal analysis by anodic stripping voltammetry: Effect of sorption by natural and model organic compounds. Water Res. 10, 605-612.

Bruckert S 1970 Influence des composés organiques solubles sur la pédogenèse en milieu acide. PhD-thesis, Université de Nancy, France. 
Buffle J, Deladoey P and Haerdi W 1978 The use of ultrafiltration for the separation and fractionation of organic ligands in fresh waters. Anal. Chim. Acta. 101, 339-357

Chen Y and Aviad T 1990 Effects of humic substances on plant growth. In Humic Substances in Soil and Crop Sciences. Eds. P MacCarthy, C E Clapp, R L Malcolm and P R Bloom. pp 161-186. American Society of Agronomy, Madison, WI, USA.

Cosovic B 1985 Aquous surface chemistry: Assessment of adsorption characteristics of organic solutes by electrochemical methods. In Chemical Processes in Lakes. Ed. W Stumm. pp 55-80. Wiley Interscience, New York, USA.

Cosovic B and Vojvodic V 1989 Adsorption behaviour of the hydrophobic fraction of organic matter in natural waters. Mar Chem. 28,183-189.

Cox J A, Comte M, Malnoe A, Burger D and Stein E A 1984 Mode of action of the regulatory protein calmodulin. In Calcium and its Role in Biology. Ed. H Siegel. pp 216-275. Marcel Dekker, New York, USA.

DeLong W A and Schnitzer M 1955 Investigation on the mobilization and transport of iron in forested soils. I. The capacities of leaf extracts and leachates to react with iron. Soil Sci. Soc. Am. Proc. 19, 360-363.

Dell'Amico C, Masciandro G, Ganni A, Ceccanti B, Garcia C, Hernandez $T$ and Costa $F 1994$ Effects of specific humic fractions on plant growth. In Humic Substances in the Global Environment and Implications on Human Health. Eds. N Senesi and T M Miano. pp 563-566. Elsevier Science B V, Amsterdam, the Netherlands.

Einhellig F A 1986 Mechanisms and modes of action of allelochemicals. In The Science of Allelopathy. Eds. A R Putnam and C S Tang. pp 171-188. John Wiley and Sons, New York, USA.

Fisher R F 1987 Allelopathy: a potential cause of forest regeneration failure. In Allelochemicals: Role in Agriculture and Forestry. Ed. G R Waller. ACS Symposium Series 330, 176-184. American Chemical Society, Washington, USA.

Grimvall A, Bengtsson M B, Boren H and Wahlström D 1991 Phytotoxic substances in runoff from forested catchment areas. In Humic Substances in the Aquatic and Terrestrial Environment. Eds. B Allard, H Boren and A Grimvall. pp 397-406. Springer, Berlin, Germany.

Jehring H 1974 Elektrosorptionsanalyse mit der Wechselstrompolarographie. Akademie Verlag, Leipzig, Germany.

Leather G R and Einhellig F A 1986 Bioassays in the study of allelopathy. In The Science of Allelopathy. Eds. A R Putnam and C S Tang. pp 133-145. John Wiley and Sons, New York, USA.

Luster J $1990 \mathrm{Cu}(\mathrm{II})$-Komplexierung durch gelöstes organisches Material in Wasserextrakten aus Laubstreu sowie durch seine Molekularfiltrations- und Umkehrphasen-ChromatographieFraktionen. PhD thesis, Swiss Federal Institute of Technology ETH, Zürich, Switzerland.

Luster J, Blaser P and Magyar B 1994 Equilibrum ion exchange method: methodology at low ionic strength and copper(II) complexation by dissolved organic matter in a leaf litter extract. Talanta 41, 1873-1880.

Lutwick L E and DeLong W A 1954 Leachates from decomposing leaves. II. Interaction with soil-forming materials. Can. J. Agric. Sci. 34, 203-213.

Mallik A U 1992 Possible role of allelopathy in growth inhibition of softwood seedlings in Newfoundland. In Allelopathy: Basic and Applied Aspects. Eds. S J H Rizvi and V Rizvi. pp 321-340. Chapman and Hall, London, UK.

Martin R B 1984 Bioinorganic chemistry of calcium. In Calcium and its Role in Biology. Ed. H Siegel. Metal ions in Biological Systems 17, 1-50. Marcel Dekker, New York, USA.

Müller T, Guggenheim G, Düggelin M and Scheidegger C 1991 Freeze-fracturing for conventional and field emission lowtemperature scanning electron microscopy: The scanning cryo unit SCU 020. J. Microsc. 161, 73-83.

Nilsson M C, Högberg P, Zackrisson O and Fengyou W 1993 Allelopathic effects by Empetrum hermaphroditum on development and nitrogen uptake by roots and mycorrhizae of Pinus silvestris. Can. J. Bot. 71, 620-628

Ochs M, Brunner I, Stumm W and Cosovic B 1993 Effects of root exudates and humic substances on weathering kinetics. Water Air Soil Pollut. 68, 213-229.

Pellissier F 1990 Allélopathie, mycorhization et les difficultés de la régénération naturelle dans les pessières subalpines. $\mathrm{PhD}$ thesis, Université de Savoie, Chambéry, France.

Plavsic M and Cosovic B 1991 Study of cadmium interaction with humic acid at the mercury/water interface. Mar. Chem. 36, 39-49.

Plavsic M, Cosovic B and Miletic S 1991 Comparison of the behaviours of copper, cadmium, and lead in the presence of humic acid in sodium chloride solutions. Anal. Chim. Acta 255, 15-21.

Pretsch E, Clerc T, Seibl J and Simon W 1981 Tabellen zur Strukturaufklärung organischer Verbindungen mit spektroskopischen Methoden. Springer Verlag, Berlin, Germany.

Rice E L 1984 Allelopathy. Academic Press, New York, USA.

Rizvi S J H, Haque H, Singh V K and Rizvi V 1992. A discipline called allelopathy. In Allelopathy: Basic and Applied Aspects. Eds. S J H Rizvi and V Rizvi. pp 1-10. Chapman and Hall, London, UK.

Rougier M 1981 Secretory activity of the root cap. In Plant Carbohydrates II: Extracellular Carbohydrates. Eds. W Tanner and F A Loewus. pp 543-574. Springer Verlag, Berlin, Germany.

Scheidegger C, Günthardt-Goerg M, Matyssek R and Hatvani P 1991 Low-temperature scanning electron microscopy of birch leaves after exposure to ozone. J. Microsc. 161, 85-95.

Senesi N, Miano T M, Provenzano M R and Brunetti G 1991 Characterization, differentiation, and classification of humic substances by fluorescence spectroscopy. Soil Sci. 152, 259-271.

Siqueira J O, Muraleedharan, Nair M G, Hammerschmidt R and Safir G R 1991 Significance of phenolic compounds in plantsoil-microbial systems. Crit. Rev. Plant Sci. 10, 63-121.

Tipping E 1990 Interactions of organic acids with inorganic and organic surfaces. In Organic Acids in Aquatic Ecosystems. Eds. E M Perdue and E T Gjessing. pp 209-221. John Wiley and Sons, Chichester, UK

Vaughan D, Malcolm R E and Ord B G 1985 Influence of humic substances on biochemical processes in plants. In Soil Organic Matter and Biological Activity. Eds. D Vaughan and R E Malcolm. pp 77-108. Kluwer Academic Publishers, Dordrecht, the Netherlands.

Wolfbeis O S 1985 The fluorescence of organic natural products. In Molecular Luminiscence Spectroscopy. Ed. S G Schulman. pp 167-370. John Wiley and Sons, New York, USA.

Section editor: $R$ Merckx 